\title{
Reinforced Concrete Panels Subjected to Uniaxial and Biaxial Tension
}

\author{
Nabil Dawood ${ }^{1}$ and Hesham Marzouk ${ }^{2}$
}

Received 13 February 2009, accepted 9 November 2009

\begin{abstract}
This paper discusses the pre- and post cracking behavior and tensile response of concrete panels subjected to axial tension. The main objective of this investigation is to study the stress-strain relationship of thick reinforced concrete plates, taking into consideration the effect of the steel reinforcement in both directions, as the thick concrete panels are well used in offshore concrete structures and nuclear power plant construction. A theoretical model for predicting the cracking behavior, which includes the crack spacing and width of reinforced concrete panels under axial loading at any given loading stage, is developed. In this theoretical model, the main parameters that influence the cracking behavior of concrete in both directions are considered. The behavior of two-way reinforced concrete plate is analyzed with consideration of the effect of concrete tensile strength, reinforcement ratio, bar diameter and spacing in both longitudinal and transverse directions.
\end{abstract}

\section{Introduction}

Concrete is reinforced with steel to deal with its inherent weakness in tension. Steel reinforcement is used to carry the tensile forces across the cracks once the concrete has exceeded its tension capacity. It can prevent cracking and avoid premature and brittle failure in structural members subjected to tensile stresses. Many research reports exist on the cracking behavior of reinforced concrete members. Rizkalla et al. $(1983$; 1984) conducted an extensive study on the cracking behavior of reinforced concrete panels with compressive strength of $34.5 \mathrm{MPa}$ and subjected to pure uniaxial tension in the presence of transverse reinforcement. Okamura et al. $(1987 ; 2003)$ studied the bond and the tension stiffening of the cracked concrete, based on that investigation, a model to introduce the average tensile stress strain for concrete was developed. Marzouk and Chen $(1993 ; 1995)$ carried out a tension study on the cracking behavior of concrete prisms under direct uniaxial tension loading and recommended a suitable softening and tension-stiffening model for high-strength concrete slabs, consideration of their post-cracking behavior and fracture energy properties. Ghali et al.(2002) discussed control of cracking of various reinforced concrete members under different loading conditions and presented many equations and methods which have been suggested for calculating crack width and spacing. Cho et al. (2004a; 2004b) conducted tension tests of six half-thickness concrete wall elements as a part of the Korea Atomic Energy Research Institute (KAERI) program, providing a test-verified analytical method for estimating the capacity of a concrete reactor containment

\footnotetext{
${ }^{1}$ Research assistant, Faculty of Engineering \& Applied Science, Memorial University of Newfoundland, Canada.

${ }^{2}$ Professor, Faculty of Engineering, Architecture and Science Ryerson University, Toronto, Ontario, Canada E-mail: hmarzouk@ryerson.ca
}

building under internal overpressurization from postulated degraded core accidents. Fields and Bischoff (2004) performed an experimental program on uniaxial tension members of both normal strength $40 \mathrm{MPa}$ and high strength $80 \mathrm{MPa}$ concrete; an empirical model for predicting the average tensile response of concrete after cracking was proposed. The cracking behavior for various reinforced concrete members under flexural and uniaxial loading were examined both experimentally and analytically by Gillbert $(2005 ; 2006)$. While the majority of concrete structures are reinforced in two directions, most of the present research work and existing analytical model equations for predicting cracking behavior take only the effect of the reinforcement in the loading direction into consideration and tend to ignore the influence of transverse reinforcement. Hence, extensive tests of reinforced concrete panels, which are reinforced in orthogonal directions and made of both normal and high strength concrete, and subjected to pure tension (uniaxial and biaxial), have been carried out to study the pre and post-cracking behavior. The objective of the research presented in this work is to develop a rational model for predicting the stress-strain, and cracking behavior of reinforced concrete panels under axial loading, taking into consideration all the main factors influencing the crack width and spacing. These factors include the tensile strength of concrete, reinforcement ratio, bar diameter and spacing in both orthogonal directions. The proposed model introduces a favorable prediction for crack spacing and width as it was compared with the experimental results of reinforced concrete panels.

\section{Experimental investigation}

In this experimental investigation, a total of nine reinforced concrete panels were fabricated and the effects of the concrete compressive strength and reinforcement ratio were investigated. The selected sizes of the tested panels were $600 \times 600 \times 190 \mathrm{~mm}$, as shown in Fig. 1. The experimental work was conducted by using a special test 


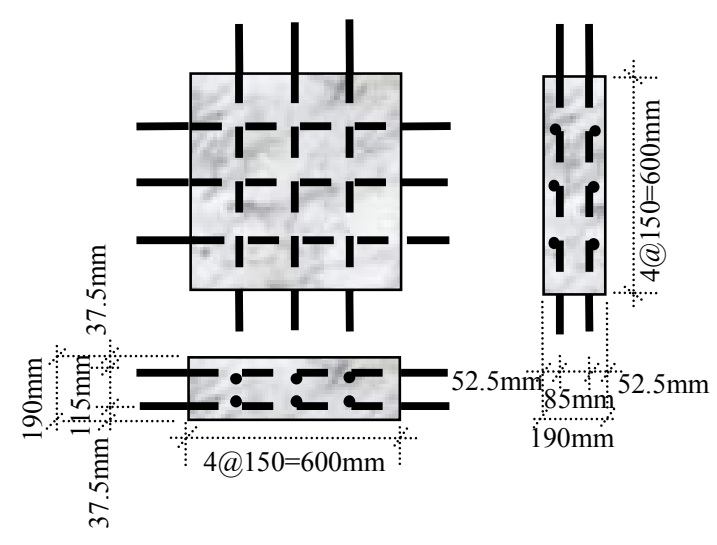

Fig. 1 Configuration and dimension of the panel.

frame that was designed and fabricated at the structural laboratory of the Memorial University of Newfoundland. The main function of this setup was to apply direct axial tension loads in one and/or two perpendicular directions, and simulate plane uniaxial and biaxial stress states. The test setup consists of three main parts, namely, fixed reaction frame; four moving walls; and 8 hydraulic jacks that were placed in between the fixed reaction frame and the moving walls, and used to apply forces on the moving walls, see Fig. 2. The fixed reaction frame was designed as a rigid and heavily reinforced concrete frame, and consequently, deformations induced in the reaction frame due to the application of the loads were negligible. Thus, the applied axial load was transmitted from hydraulic jacks to the specimens independently in both directions.

All the specimens in the experimental program were reinforced in two perpendicular directions with deformed bars in two layers, and the longitudinal reinforcements were spaced at 150 and $300 \mathrm{~mm}$. The main variables considered in the test program were the concrete strength, reinforcement ratio, and applying the load in unixial or biaxial directions. Two levels of compressive strength were used to cast specimens. The average concrete compressive strength $f_{c}^{\prime}$ was found equal to $(35-40) \mathrm{MPa}$ for normal strength concrete specimens, and (75-90) $\mathrm{MPa}$ for high strength concrete specimens. Three control cylinders having a nominal diameter of $100 \mathrm{~mm}$ and height of $200 \mathrm{~mm}$ were cast at the same time as the specimens to relate specimen strength to standard material test results. The reinforcing bars are Grade 400 steel conformed to CAN/CSA-G40.20-M92 Canadian Specifications. The reinforcement used in the segments consisted of deformed bars of $15 \mathrm{~mm}$ and $20 \mathrm{~mm}$ in diameter with yield stress and ultimate tensile strength of $400 \mathrm{MPa}$, and $650 \mathrm{MPa}$, respectively. The steel bars had a modulus of elasticity of $200 \mathrm{GPa}$. Two reinforcement ratios were used; $1.2 \%$, and $2 \%$. The load was applied in uniaxial and biaxial directions. For the biaxial case, the loading was equally applied in the orthogonal direction, where the loading ratio was equal to $1: 1$. The concrete cover to bar diameter $\left(\mathrm{C}_{\mathrm{c}} / \mathrm{d}_{\mathrm{b}}\right)$ ratio was fixed equal to 2.50 . The bar spacing was $150 \mathrm{~mm}$, and $300 \mathrm{~mm}$, as shown in Table 1. All specimens were moist-cured for at least three weeks and then air-dried until testing. The strains of the steel bars were typically measured by strain gages affixed to the bars, as shown in Fig. 3(a). Figure 3(b)

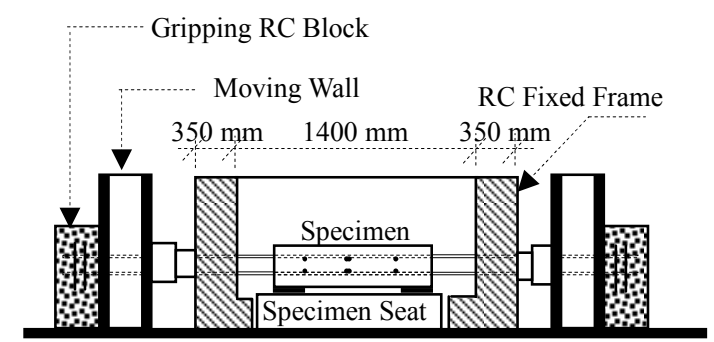

(a) Elevation

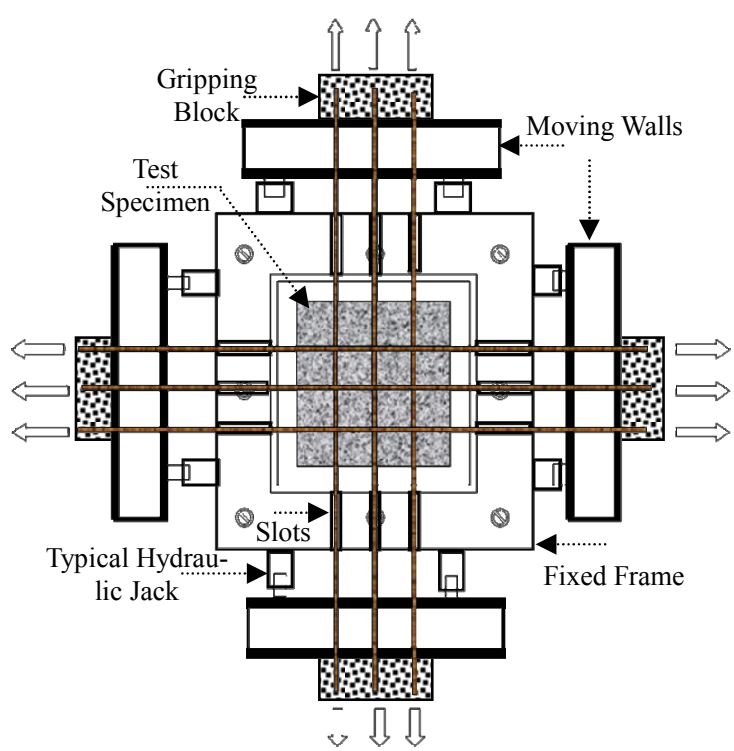

(b) Plan

Fig. 2 Test setup.

Table 1 Reinforced concrete panel segments of the experimental program.

\begin{tabular}{|c|c|c|c|c|c|}
\hline $\begin{array}{c}\text { Specimens } \\
\text { Symbol }\end{array}$ & $\begin{array}{c}\text { Specimens } \\
\text { Dimensions } \\
(\mathrm{mm})\end{array}$ & $\begin{array}{c}f_{\mathrm{c}}^{\prime} \\
\mathrm{MPa}\end{array}$ & $\begin{array}{c}\mathrm{d}_{\mathrm{b}} \\
\mathrm{mm}\end{array}$ & $\begin{array}{l}\mathrm{C}_{\mathrm{c}} / \mathrm{d}_{\mathrm{b}} \\
\text { Ratio }\end{array}$ & $\rho \%$ \\
\hline NS-U-15-2.5-6 & \multirow{9}{*}{$600 \times 600 \times 190$} & 40 & 15 & 2.5 & 1.2 \\
\hline HS-U-15-2.5-6 & & 90 & 15 & 2.5 & 1.2 \\
\hline NS-B-15-2.5-6 & & 35 & 15 & 2.5 & 1.2 \\
\hline HS-B-15-2.5-6 & & 75 & 15 & 2.5 & 1.2 \\
\hline HS-U-20-2.5-6 & & 75 & 20 & 2.5 & 2 \\
\hline HS-U-20-2.5-6 & & 75 & 20 & 2.5 & 2 \\
\hline HS-U-20-2.5-4 & & 80 & 20 & 2.5 & 1.2 \\
\hline HS-U-20-2.5-4 & & 70 & 20 & 2.5 & 1.2 \\
\hline HS-U-20-2.5-4* & & 70 & 20 & 2.5 & 1.2 \\
\hline
\end{tabular}

NS: Normal Strength Concrete, HS: High Strength Concrete, U: Uniaxial Tension Loading, B: Biaxial Tension Loading, 6: No. of bars in each direction,

* Panel without transverse reinforcement. 


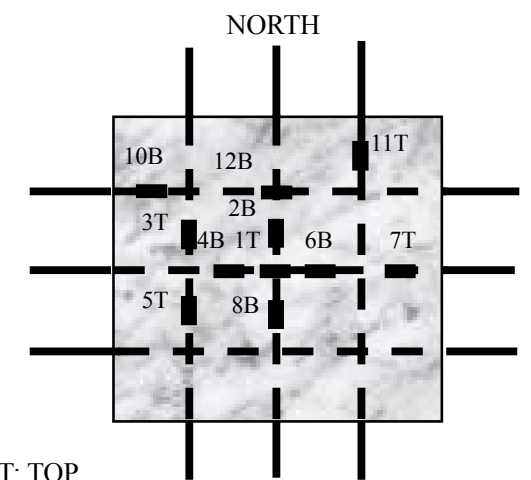
B: BOTTOM

(a)

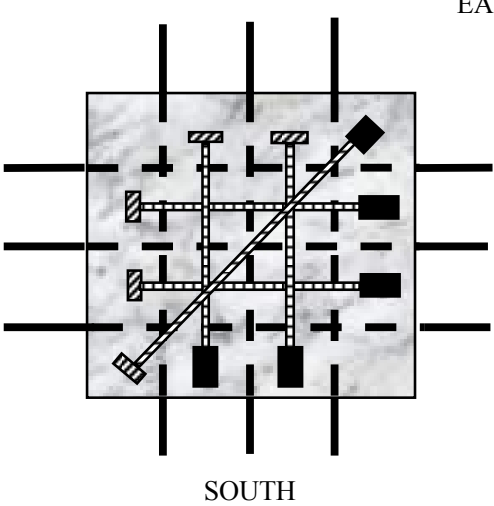

(b)

Fig. 3 (a) Location of strain gages, (b) location of LPDTs.

shows five linear displacement transducers (LPDTs) that were attached to the concrete surface for measuring deformations and cracking properties. The data was collected and processed automatically using a data acquisition system.

\section{Theoretical model for a concrete plate under tension}

\subsection{Behavior before cracking}

The concrete strain is taken to be zero when the concrete is cast. Thus, the length of the concrete member at the time of casting is defined as the undeformed length of the member, L. The axial deformation measured from this undeformed condition will be called $\Delta$. So, the concrete strain, which is assumed to be uniform both over the cross section and along the length of the member, is given by $\varepsilon_{t}=\Delta / \mathrm{L}$, assuming that the concrete and reinforcement bars are all rigidly anchored together. Hence, any change in length of the concrete must be accompanied by an identical change in the length of the reinforcement $\left(\varepsilon_{t}=\varepsilon_{s}\right)$. For the equilibrium requirement, the internal stresses balance the applied load. Prior to cracking, the steel reinforcement and concrete behave elastically and tensile force $\mathrm{P}$ in a panel is resisted partly by concrete and partly by the main longitudinal reinforcement in accordance to the stiffness of the concrete and steel bar sections (Hsu et al. 1994; 1996).

$$
\begin{aligned}
P & =P_{c}+P_{s} \\
& =\left(E_{c} A_{c}+E_{s} A_{s}\right) \varepsilon_{t} \\
\sigma_{t} & =\frac{P}{A_{c}}-\rho E_{s} \varepsilon_{t}
\end{aligned}
$$

where $\varepsilon_{t}$ is the tensile strain of concrete, $\mathrm{P}_{\mathrm{c}}$ and $\mathrm{P}_{\mathrm{s}}$ are the loads carried by the concrete and reinforcement, and $\mathrm{A}_{\mathrm{c}}$ and $\mathrm{A}_{\mathrm{s}}$ are the cross sectional areas of the concrete and reinforcement. At cracking, $\varepsilon_{t}=\varepsilon_{t}^{\prime}$, and $P=P_{c r}$,

$$
\begin{aligned}
& P_{c r}=f_{t}^{\prime} A_{c}+E_{s} A_{s} \varepsilon_{t}^{\prime} \\
& f_{t}^{\prime}=\frac{P_{c r}}{A_{c}}-\rho E_{s} \varepsilon_{t}^{\prime}
\end{aligned}
$$

where $\rho=A_{s} / A_{c}$, the reinforcement ratio for the net cross-sectional area of concrete; $P_{c r}$ is load that causes the cracking of the concrete section; $\varepsilon_{t}^{\prime}$ is the strain of the concrete at cracking loading stage. At the first crack appearance, the slope of the member stress-strain curve is radically decreases up to the yield point of the reinforcement with continuous variation of the slope through each crack occurrence.

Figure 4 represents a comparison between the loads carried by the concrete section calculated from Eq. (1), where this equation considers the compatibility condition between the concrete section and the surrounding reinforcement, and the calculated value of the load carried by the same section considering the share of the total load between the concrete section and reinforcement according to their relative stiffness as follows:

$$
P_{c}=\left(\frac{1}{1+n \rho}\right) P \quad, \quad P_{s}=\left(\frac{n \rho}{1+n \rho}\right) P
$$

Prior to the cracking of the concrete member, steel reinforcement and concrete behave elastically and there is a compatibility condition between the concrete and reinforcing steel bars (Belarbi and Hsu 1994; and Jae et al. 2004), as illustrated in Fig. 4. The concrete and steel

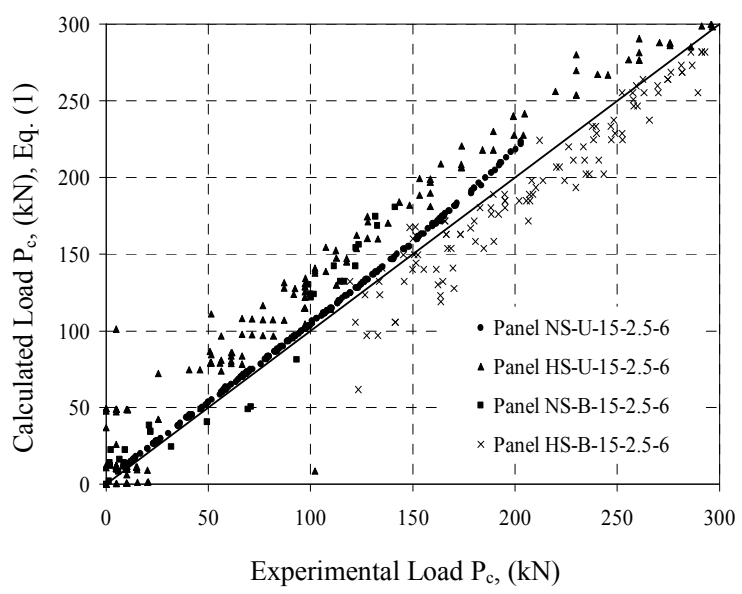

Fig. 4 Load carried by concrete section. 
bars share the applied load in accordance to the stiffness of each material without any slippage between them. These stresses and strains can be approximately related by a straight line expressed as:

$$
\sigma_{t}=E_{c} \varepsilon_{t}
$$

The normalized concrete stresses $\sigma_{t} / f_{t}^{\prime}$ obtained from Eq. (2), and their corresponding measured strains $\varepsilon_{t}$ are plotted in Fig. 5. These stresses and strains can be expressed by straight line as shown in the following equation:

$$
\frac{\sigma_{t}}{f_{t}^{\prime}}=\frac{\varepsilon_{t}}{102 \times 10^{-6}}
$$

Table 2 presents the calculated tensile cracking stress $f_{t}^{\prime}$ from Eq. (4), as well as the cracking strain $\varepsilon_{t}^{\prime}$ observed for each panel segment experimentally, where the cracking strain is picked out at the very point as the slope of stress-strain curve abruptly changes. The average value for all the measured cracking strains for each panel tested in the experimental program conducted in the present study is found to be about 102 microstrain. The average of the cracking stress is found to be related to the square root of the cylinder compression strength for the normal strength concrete specimens as:

$$
f_{t}^{\prime}=0.34 \sqrt{f_{c}^{\prime}}(\mathrm{MPa})
$$

The average modulus of elasticity of the normal strength concrete can be obtained by substituting Eqs. (6) and (8) into Eq. (7):

$$
E_{c}=3330 \sqrt{f_{c}^{\prime}}(\mathrm{MPa})
$$

For high strength concrete the cubic root of the compressive stress $\left(f_{c}^{1 / 3}\right)$ provides a good representation of the tensile strength for the high strength concrete (Alavi-Fard, and Marzouk 2002; Marzouk, and Chen 1995), as presented in the following equation:

$$
f_{t}^{\prime}=\beta \sqrt[3]{f_{c}^{\prime}} \quad(\mathrm{MPa})
$$

where $\beta$ is a coefficient ranging from $0.6-0.7$.

Also, the average value of the modulus of elasticity of

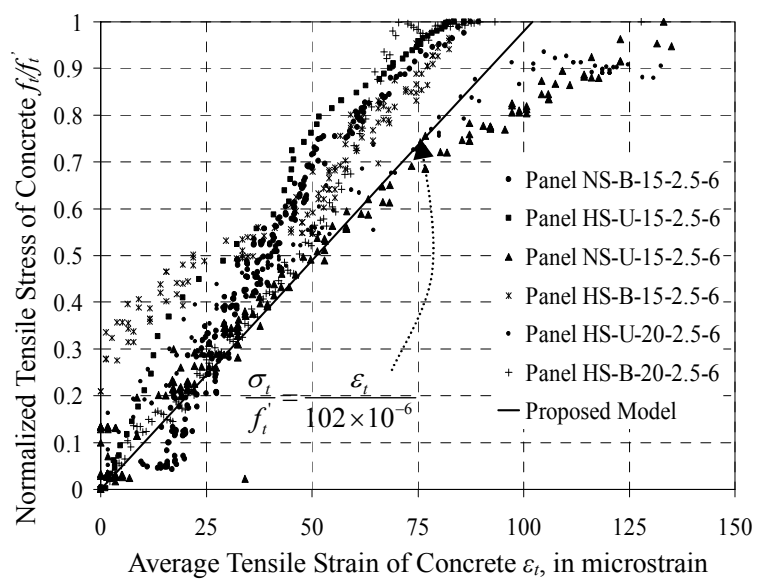

Fig. 5 Ascending branch of tensile stress-strain curves of concrete.

the high strength concrete can be attained by substituting Eqs. (6) and (10) into Eq. (7):

$$
E_{c}=6400 \sqrt[3]{f_{c}^{\prime}} \quad(\mathrm{MPa})
$$

For both NSC and HSC, the CEB-FIP Model Code and EC2-2004 Code link the elastic modulus $\mathrm{E}_{\mathrm{c}}$ to the compressive strength $f_{c}^{\prime}$ according to:

$$
E_{c}=22000\left(\frac{f_{c}^{\prime}}{10}\right)^{\frac{1}{3}}
$$

In Eq. $12 \mathrm{E}_{\mathrm{c}}$ and $f_{c}^{\prime}$ are measured in MPa.

In the case of HSC, in the formula proposed by ACI committee 363 , the elastic modulus of concrete is expressed as following:

$$
E_{c}=\left[3321\left(f_{c}^{\prime}\right)^{0.5}+6895\right] \cdot(\gamma / 2300)^{1.5}
$$

In Eq. 13, Ec and $f_{c}^{\prime}$ are measured in MPa, and $\gamma$ in $\mathrm{kg} / \mathrm{m}^{3}$.

Similarly, the Architectural Institute of Japan (AIJ) specifies the following equation to estimate the modulus of elasticity of concrete:

Table 2 Summary of the test results.

\begin{tabular}{|c|c|c|c|c|c|c|c|}
\hline Specimen & $f_{c}^{\prime}, \mathrm{MPa}$ & $P_{c r(e x)}, \mathrm{kN}$ & $\varepsilon_{c r(e x)}$, microstrain & $\begin{array}{c}f_{t}^{\prime}, \text { Eq.(4) } \\
\mathrm{MPa}\end{array}$ & $\begin{array}{c}\sigma_{\text {scr(ex), }} \mathrm{MPa} \\
\mathrm{MPa}\end{array}$ & $\begin{array}{c}\mathrm{E}_{\mathrm{c}(\mathrm{ex})}, \\
\mathrm{MPa}\end{array}$ & $\begin{array}{c}\mathrm{E}_{\mathrm{c}}, \text { Eqs. (9) or (11) } \\
\mathrm{MPa}\end{array}$ \\
\hline NS-U-15-2.5-6 & 40 & 240 & 89.39 & 2.06 & 224 & 19740 & 21000 \\
\hline HS-U-15-2.5-6 & 90 & 400 & 133.12 & 3.2 & 340 & 29154 & 28600 \\
\hline NS-B-15-2.5-6 & 35 & 220 & 90.99 & 1.92 & 200 & 19080 & 19700 \\
\hline HS-B-15-2.5-6 & 75 & 310 & 96.536 & 2.72 & 292 & 27900 & 26900 \\
\hline HS-U-20-2.5-6 & 75 & 360 & 113 & 3.07 & 186 & 26283 & 26900 \\
\hline HS-B-20-2.5-6 & 75 & 335 & 97.56 & 2.96 & 167 & 29750 & 26900 \\
\hline HS-U-20-2.5-4 & 80 & 330 & 115.5 & 3.0 & 270 & 26250 & 27600 \\
\hline HS-B-20-2.5-4 & 70 & 315 & 85.4 & 2.7 & 260 & 28270 & 26500 \\
\hline HS-U-20-2.5-4 & 70 & 350 & 94.3 & 2.82 & 290 & 26450 & 27600 \\
\hline
\end{tabular}




$$
E_{c}=21000\left(f_{c}^{\prime} / 20\right)^{\frac{1}{2}} \cdot(\gamma / 2300)^{1.5}
$$

In Eq. 14, Ec and $f_{c}^{\prime}$ are measured in $\mathrm{MPa}$, and $\gamma$ in $\mathrm{kg} / \mathrm{m}^{3}$. The available experimental results conducted by Belarbi and Hsu (1994), and Cho et al. (2004b) are used to verify the accuracy of the proposed equation for calculating the modulus of elasticity of concrete. Comparison for the concrete modulus of elasticity between the proposed model presented in Eq.11 and the equations of CEB-FIP 1990, ACI-363, and AIJ-1985 is presented in Table 3.

\subsection{Behavior after cracking}

As shown in Fig. 6, a reinforced concrete member is subjected to an axial tensile force P. At the two cracks indicated, the steel carries all the tensile force at the stress designated as $\sigma_{\mathrm{s} 0}$. Stress concentration was noted at the intersection of two orthogonal bars due to the effect of the transverse bars (Rizkalla et al. 1983). When the longitudinal bars in X-direction are stretched, the concrete surrounding the bars will resist the transverse bars. Thus, the transverse bars in the perpendicular direction can be assumed to bear against the concrete, causing additional force component $\left[\sigma_{b b}(\mathrm{x}) \Phi_{2} S_{1}\right]$ at the intersection between the longitudinal bars and the transverse bars. This additional component, which reflects the in-

Table 3 Concrete modulus of elasticity of concrete.

\begin{tabular}{|c|c|c|c|c|c|c|}
\hline Specimen & $\begin{array}{c}f_{c}^{\prime} \\
\mathrm{MPa}\end{array}$ & $\begin{array}{l}\mathrm{E}_{\mathrm{c}(\mathrm{ex})}, \\
\mathrm{MPa}\end{array}$ & $\begin{array}{c}\text { CEB- } \\
\text { FIP } \\
1990\end{array}$ & $\begin{array}{l}\text { ACI- } \\
363\end{array}$ & $\begin{array}{l}\text { AIJ- } \\
1985\end{array}$ & $\begin{array}{c}\text { Proposed } \\
\text { Model }\end{array}$ \\
\hline E1.5-1B ${ }^{*}$ & 39 & 23800 & 34600 & 31300 & 33200 & 21800 \\
\hline E2-1 ${ }^{*}$ & 48 & 27200 & 37100 & 33800 & 36800 & 23300 \\
\hline E2'-1 ${ }^{*}$ & 40 & 24000 & 34900 & 31600 & 33600 & 22000 \\
\hline E2"-1" & 41 & 24600 & 35200 & 31900 & 34000 & 22100 \\
\hline E2-1A ${ }^{*}$ & 45 & 24600 & 36300 & 33000 & 35600 & 22800 \\
\hline E4-1 ${ }^{*}$ & 41 & 26000 & 35200 & 31900 & 34000 & 22100 \\
\hline${\mathrm{E} 4-5^{*}}^{*}$ & 39 & 22900 & 34600 & 31300 & 33200 & 21800 \\
\hline E4-1A ${ }^{*}$ & 38 & 24000 & 34300 & 31000 & 32800 & 21600 \\
\hline E10-1 ${ }^{*}$ & 41 & 22000 & 35200 & 31900 & 34000 & 22100 \\
\hline E10-1A ${ }^{*}$ & 37 & 24900 & 34000 & 30700 & 32300 & 21500 \\
\hline E10-1B ${ }^{*}$ & 40 & 23000 & 34900 & 31600 & 33600 & 22000 \\
\hline R4-1 ${ }^{*}$ & 42 & 22000 & 35500 & 32200 & 34400 & 22300 \\
\hline R10-1* & 40 & 19500 & 34900 & 31600 & 33600 & 22000 \\
\hline R30-1 ${ }^{*}$ & 41 & 26900 & 35200 & 31900 & 34000 & 22100 \\
\hline CL-U-R1-1 ${ }^{* *}$ & 44 & 17228 & 36000 & 32800 & 35200 & 22500 \\
\hline CL-B-R1-1 ${ }^{* *}$ & 44 & 16850 & 36000 & 32800 & 35200 & 22500 \\
\hline CL-B-R1-2 ${ }^{* *}$ & 48.1 & 24102 & 37000 & 33900 & 36900 & 23200 \\
\hline CL-B-R1-3** & 39.1 & 19979 & 34000 & 31300 & 33200 & 21700 \\
\hline CL-U-R2-1 ${ }^{* *}$ & 46.2 & 14808 & 36000 & 33300 & 36100 & 22900 \\
\hline CL-B-R2-1 ${ }^{* *}$ & 36.6 & 12052 & 33000 & 30500 & 32100 & 21200 \\
\hline CL-B-R2-2 & 40 & 14510 & 34000 & 31600 & 33600 & 22000 \\
\hline CL-B-R2-3** & 39.1 & 18942 & 34600 & 31300 & 33200 & 21700 \\
\hline CL-U-R3-1 ${ }^{* *}$ & 46.2 & 18381 & 36600 & 33300 & 36100 & 22900 \\
\hline \multicolumn{3}{|c|}{ Mean $(\mu)$ for $\mathrm{E}_{\text {(ex })} / \mathrm{E}_{\text {(Cal.) }}$} & 0.61 & 0.67 & 0.62 & 0.98 \\
\hline \multicolumn{3}{|c|}{$\begin{array}{c}\text { Standard Deviation }\left(\sigma^{2}\right) \text { for } \\
\mathrm{E}_{(\mathrm{ex})} / \mathrm{E}_{(\text {(Cal.) }}\end{array}$} & 0.117 & 0.131 & 0.124 & 0.121 \\
\hline \multicolumn{3}{|c|}{$\begin{array}{l}\text { Coefficient of Variance }\left(\sigma^{2} / \mu\right) \\
\text { for } E_{(\mathrm{ex})} / \mathrm{E}_{(\mathrm{Cal.})}\end{array}$} & $19.2 \%$ & $\%$ & 0 & 0 \\
\hline
\end{tabular}

${ }_{* *}^{*}$ Experimental Program Conducted by Belarbi and Hsu (1994).

** Experimental Program Conducted by Jae et al. (2004). fluence of the presence of the transverse bars, is assumed to be uniformly distributed along the longitudinal bar locations. Thus, the longitudinal equilibrium of forces at any section $X$ between the two cracks leads to:

$$
\begin{aligned}
P & =A_{s} \sigma_{s 0} \\
& =A_{s} \sigma_{s}(x)+A_{c} \sigma_{c}(x)+\frac{2 \sigma_{b b}(x) \phi_{2} S_{1}}{S_{2}} X
\end{aligned}
$$

where $\sigma_{b b}$ is the bearing stress; $S_{I}$ is the bar spacing in $X$-direction, $S_{2}$ is the transverse bar spacing, $\varnothing_{2}$ is the transverse bar diameter in the perpendicular direction, and $X$ is the distance from the crack face. For simplicity, it can be assumed that the average bearing stress $\sigma_{b b}$ is half of the tensile strength concrete (Desayi 1976). The third term in the right hand side of Eq. (15) represents the influence of the transverse bars on the steel stress distribution, see Fig. 6. The estimated steel stress at the crack location can be expressed from Eq. (15), by dividing both sides of Eq. (15) by $A_{s}=\pi \Phi^{2} / 4$, as follows:

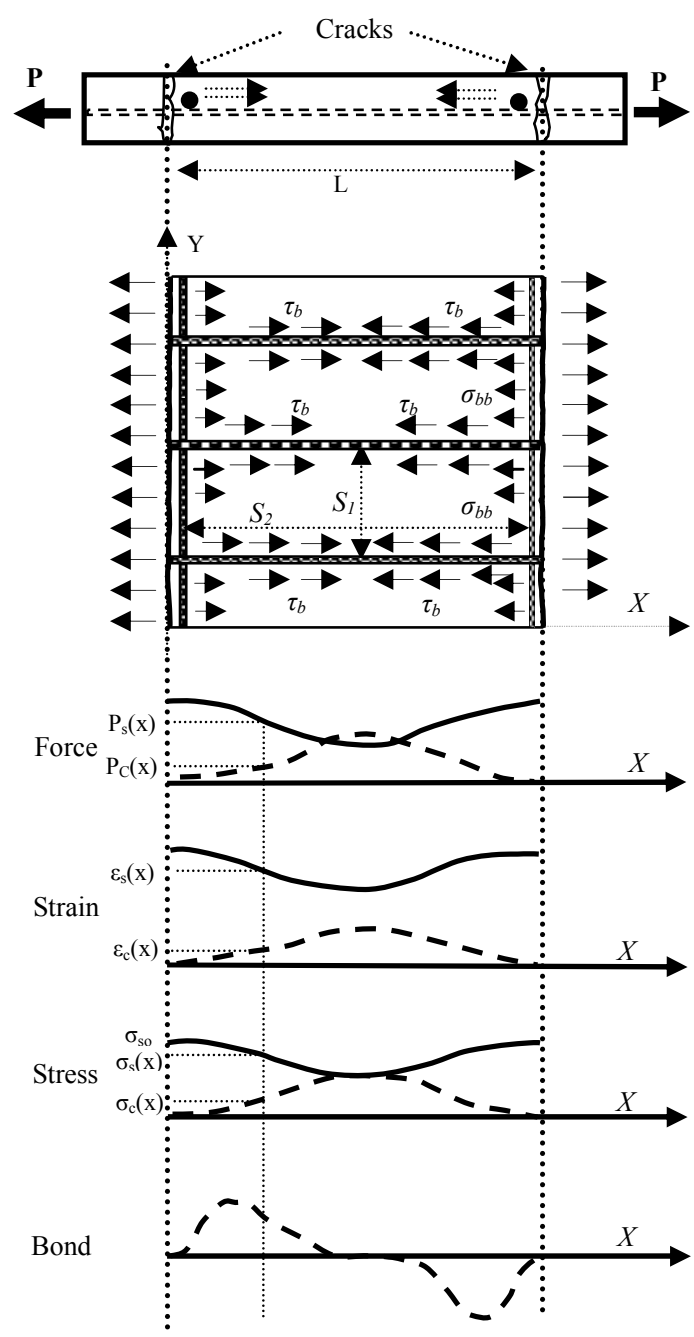

Fig. 6 Schematic distribution of forces, strains, normal stresses, and bond stresses along a cracked reinforced concrete member. 


$$
\sigma_{s 0}=\sigma_{s}(x)+\frac{1}{\rho} \sigma_{c}(x)+\frac{8 \sigma_{b b}(x) S_{1} \phi_{2}}{\pi \phi_{1}^{2} S_{2}} X
$$

Eq. (16) states that at any section between the two cracks, the sum of the steel stress $\sigma_{\mathrm{s}}(\mathrm{x})$, concrete stress $\sigma_{\mathrm{c}}(\mathrm{x})$ divided by $\rho$, and the contribution of the transverse reinforcement must be equal to the steel stress at the cracked section $\sigma_{s 0}$.

The steel strain $\varepsilon_{\mathrm{s}}(\mathrm{x})$ and concrete strain $\varepsilon_{\mathrm{c}}(\mathrm{x})$ are also sketched in Fig. 6. The steel strain $\varepsilon_{\mathrm{s}}(\mathrm{x})$ decreases from a maximum at the crack to a minimum at the mid-point between the two cracks. In contrast, the concrete strain $\varepsilon_{\mathrm{c}}(\mathrm{x})$ should be zero at the crack location while it increases to a maximum at the mid-point. The difference between $\varepsilon_{\mathrm{s}}(\mathrm{x})$ and $\varepsilon_{\mathrm{c}}(\mathrm{x})$ is caused by the slip between the steel bar and surrounding concrete.

Denoting the average steel strain over several cracks by $\varepsilon s x$, the relationship between stress and strain in $\mathrm{x}$-direction is obtained by the following equations:

$$
\varepsilon_{s x}=\frac{1}{L} \int_{0}^{L} \varepsilon_{s}(x) d x
$$

Noting that $\varepsilon_{\mathrm{s}}(\mathrm{x})=\sigma_{\mathrm{s}}(\mathrm{x}) / \mathrm{E}_{\mathrm{s}}$ before the first yielding of the steel:

$$
\varepsilon_{s x}=\frac{1}{E_{s}}\left(\frac{1}{L} \int_{0}^{L} \sigma_{s}(x) d x\right)
$$

The part in parentheses can be defined as an average stress of reinforcement $\sigma_{\mathrm{s}}$

$$
\begin{aligned}
& \sigma_{s}=\frac{1}{L} \int_{0}^{L} \sigma_{s}(x) d x \\
& \varepsilon_{s x}=\frac{\sigma_{s}}{E_{s}}
\end{aligned}
$$

Similarly, averaging the stresses on the right side of Eq. (16) along the length L gives:

$$
\sigma_{s 0}=\frac{1}{L} \int_{0}^{L} \sigma_{s}(x) d x+\frac{1}{\rho}\left(\frac{1}{L} \int_{0}^{L} \sigma_{c}(x) d x\right)+\frac{8 \sigma_{b b} S_{1} \phi_{2}}{\pi \phi_{1}^{2} S_{2}} X
$$

The variable enclosed by the parentheses of the second term is defined as the average concrete stress in tension and expressed as:

$$
\sigma_{x}=\left(\frac{1}{L} \int_{0}^{L} \sigma_{c}(x) d x\right)
$$

Then Eq. (18) becomes:

$$
\sigma_{s 0}=\sigma_{s}+\frac{1}{\rho} \sigma_{x}+\frac{8 \sigma_{b b} S_{1} \phi_{2}}{\pi \phi_{1}^{2} \cdot S_{2}} X
$$

where the third term reflects the effect on the transverse reinforcements on the steel stress distribution. It is found that the transverse reinforcement causes stress concen- tration at the intersection with the longitudinal reinforcement and can cause an increase in the forces transferred from the steel reinforcement to the concrete section. Based on the experimental investigation, at cracking stage, the measured value of the average steel stress embedded in the concrete section $\left(\sigma_{\mathrm{s}}\right)$ is found to be approximately $340 \mathrm{MPa}$ for panel HS-U-15-2.5-6; and the stress caused by the transverse bars represents about $8 \%$ from the value of $\sigma_{\mathrm{s}}$, however this value decreases to $5 \%$ at the steel yielding stage. For the sake of simplicity, the influence of the transverse bar on the steel stress distribution can be expressed by a factor $\alpha$, where the value of $\alpha$ is found to be equal to approximately between $0.92-0.95$.

Substituting $\sigma_{\mathrm{s}}=\mathrm{E}_{\mathrm{s}} \cdot \varepsilon_{\mathrm{sx}}$ from Eq. (20) into Eq. (23), the relationship between the average concrete stress after the cracking stage $\left(\sigma_{\mathrm{x}}=\mathrm{ft}\right)$, and average strain $\varepsilon_{\mathrm{sx}}$ is derived as:

$$
\begin{aligned}
\sigma_{x} & =\rho\left(\sigma_{s 0}-\sigma_{s}-\frac{8 \sigma_{b b} S_{1} \phi_{2}}{\pi \phi_{1}^{2} S_{2}} X\right) \\
& =\rho\left(\frac{P}{A_{s}}-\alpha E_{s} \varepsilon_{s x}\right)=\frac{P}{A_{c}}-\alpha \rho E_{s} \varepsilon_{s x}
\end{aligned}
$$

By plotting the normalized value of the concrete stress $\sigma_{t} / f_{t}^{\prime}$ versus \&t for all load stages, an experimental tensile stress-strain curve for concrete after cracking for each test panel, as shown in Fig. 7.

\section{Tension stiffness model for concrete plate}

Tension stiffening phenomenon can be defined as the increase in stiffness in a reinforced concrete member due to the interaction between concrete and reinforcement. As a member cracks, concrete between cracks rebound to its original state but is restrained by the reinforcement. The concrete between cracks is still able to develop ten-

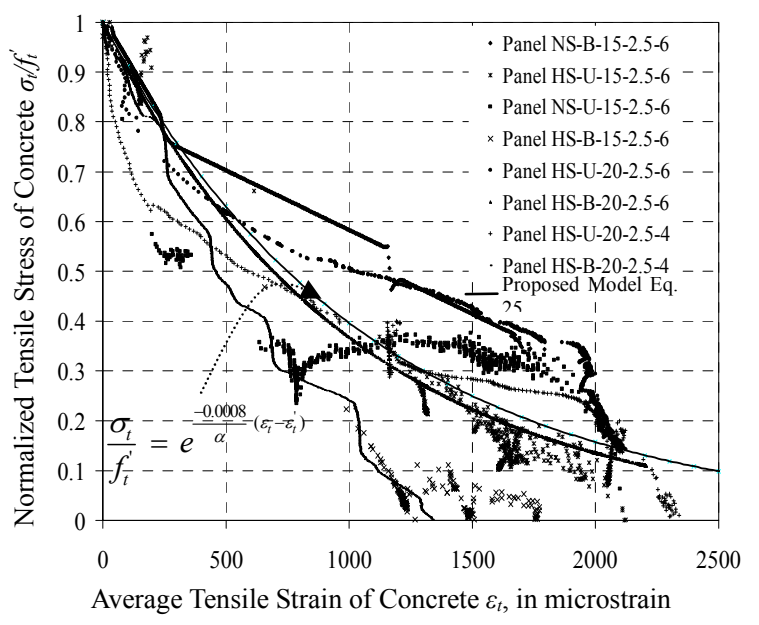

Fig. 7-Descending branch of tensile stress-strain curves of concrete. 
sile stresses away from the crack as load is transferred from the reinforcing steel back into the surrounding concrete, resulting in some tensile stresses in the concrete. A new approach for the post cracking stress strain of reinforced concrete member in tension is defined. It was found that the best mathematical form to fit the descending branch of the experimental stress-strain curve is shown in Fig. 7.

$$
\frac{\sigma_{t}}{f_{t}^{\prime}}=e^{\frac{-0.0008}{\alpha}\left(\varepsilon_{t}-\varepsilon_{t}^{\prime}\right)}
$$

where $\sigma_{t} / f_{t}{ }^{\prime}$ represents the normalized tensile stress, $\varepsilon_{t}$ is the measured member strain $(\Delta / \mathrm{L})$, and $\alpha$ in both Eqs. (24) and (25) reflects the influence of the transverse reinforcement bars on the constitutive laws for the stress-strain relationship of concrete in tension. A similar effective concrete tensile stress-strain relationship after cracking was originally proposed by (Rizkalla et al. 1984), and (Fields and Bischoff 2004) verified its validity.

Figure 8 shows a comparison of the previously proposed models (Rizkalla et al. 1984; Shima and Okamura 1987; Marzouk and Chen 1993; Fields and Bischoff 2004), inclusive of the proposed model in Eq. (7) for the ascending portion, and Eq. (25) in the descending portion in this study. All of these models were obtained from the experimental study for the behavior reinforced concrete members under axial loading. It is noted that the proposed model represents an average value between the previously proposed models for tensile stress-strain response of reinforced concrete, as shown in Fig. 8. Based on the experimental results, the presence of the transverse reinforcement in the concrete panels appears to cause a reduction in the tension stiffening response and a consequence increase in the crack width (Dawood and Marzouk 2008; Williams 1986).

A comparison for the stress-strain response of reinforced HSC panels reinforced with transverse rein-

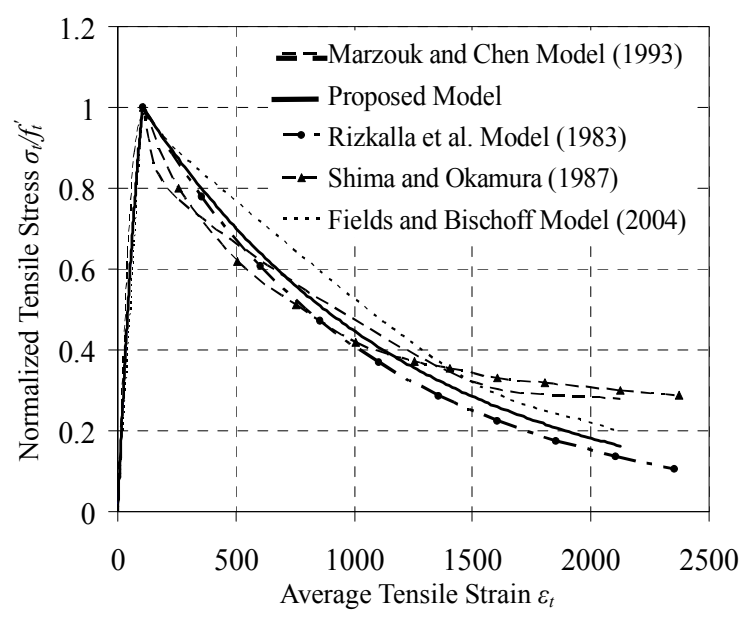

Fig. 8 Average stress strain of concrete.

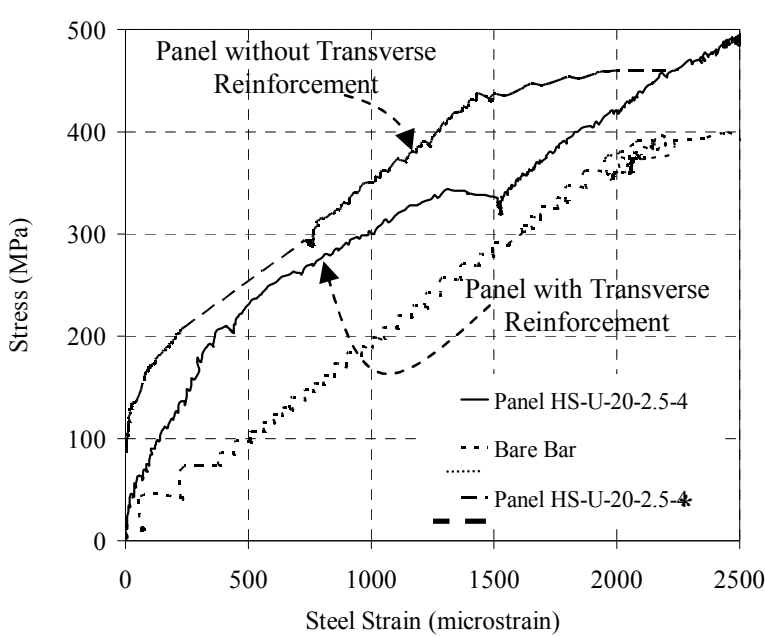

Fig.9 Effect of transverse reinforcement on the tension stiffening response.

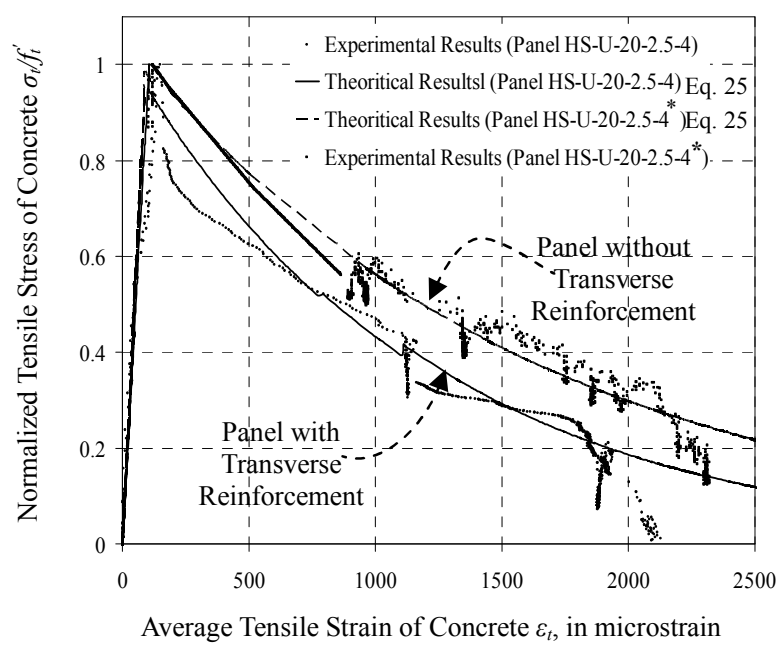

Fig.10 Effect of transverse reinforcement on average stress-strain curves of concrete.

forcement (panel HS-U-20-2.5-4) and without transverse reinforcement (panel HS-U-20-2.5-4*), is presented in Fig. 9. Also, Fig. 10 presents a comparison of the average stress-strain curves of concrete between panels HS-U-20-2.5-4, and HS-B-20-2.5-4* . It is evident that prior to cracking stage, a slight difference behavior of the tensile stress-strain response is observed. However, after cracking stage the effect of the presence of transverse reinforcement becomes more obvious. Generally, the panel with the transverse reinforcement shows lower tension stiffening contribution of concrete for different steel stress levels in comparison to the identical panel without transverse reinforcement.

Furthermore, the transverse reinforcement has an effect on the cracking behavior of the HSC panels. the measured average crack spacing for panels HS-U-20-2.5-4, and HS-U-20-2.5-4* is found to be 240 $\mathrm{mm}$ and $265 \mathrm{~mm}$, consequently, the presence of the 
Table 4 Measured and calculated average crack spacing of thick reinforced concrete plates.

\begin{tabular}{|c|c|c|c|c|c|c|}
\hline $\begin{array}{c}\text { Specimen } \\
\text { Serial }\end{array}$ & $\begin{array}{c}\text { Specimen } \\
\text { Number }\end{array}$ & $\begin{array}{c}\text { Measured Average } \\
\text { Crack spacing } \\
(\mathrm{mm})\end{array}$ & $\begin{array}{c}\text { Beeby } \mathrm{S}_{\mathrm{b}} \\
\text { Equation } \\
(\mathrm{mm})\end{array}$ & $\begin{array}{c}\text { Leonhard } \mathrm{S}_{\mathrm{L}} \\
\text { Equation } \\
(\mathrm{mm})\end{array}$ & $\begin{array}{c}\text { Rizkalla } \\
\text { Equation } \\
(\mathrm{mm})\end{array}$ & $\begin{array}{c}\text { Proposed } \\
\text { Model S } \\
(\mathrm{mm})\end{array}$ \\
\hline 1 & NS-B-15-2.5-6 & 151 & 139.9 & 203.3 & 178.9 & 155.9 \\
\hline 2 & NS-B-15-2.5-6 & 144 & 139.9 & 186.1 & 178.9 & 148.5 \\
\hline 3 & HS-U-15-2.5-6 & 152 & 139.9 & 238.9 & 178.9 & 166.9 \\
\hline 4 & HS-B-15-2.5-6 & 151 & 139.9 & 211.9 & 178.9 & 157 \\
\hline 5 & HS-U-20-2.5-6 & 150 & 133.2 & 172 & 197.2 & 156.6 \\
\hline 6 & HS-B-20-2.5-6 & 148 & 133.2 & 159.5 & 197.2 & 147.2 \\
\hline 7 & HS-U-20-2.5-4 & 240 & 186.5 & 268.3 & 261.2 & 250 \\
\hline 8 & HS-B-20-2.5-4 & 275 & 186.5 & 245.3 & 261.2 & 265 \\
\hline 9 & HS-B-20-2.5-4 & 255 & 186.5 & 253.5 & 261.2 & 265 \\
\hline \multicolumn{2}{|c|}{ Mean $(\mu)$ for $\mathrm{S}_{\mathrm{m}(\mathrm{ex})} / \mathrm{S}_{\mathrm{m}(\text { tho. })}$} & 1.159 & 0.835 & 0.853 & 0.971 \\
\hline \multicolumn{2}{|r|}{ Standard Deviation $(\sigma)$ for $\mathrm{S}_{\mathrm{m}(\mathrm{ex})} / \mathrm{S}_{\mathrm{m}(\text { tho })}$} & 0.149 & 0.152 & 0.097 & 0.037 \\
\hline \multicolumn{2}{|r|}{ Coefficient of Variance $(\sigma / \mu)$ for $\mathrm{S}_{\mathrm{m}(\mathrm{ex})} / \mathrm{S}_{\mathrm{m}(\text { tho })}$} & $12.8 \%$ & $18.2 \%$ & $11.4 \%$ & $3.8 \%$ \\
\hline
\end{tabular}

transverse reinforcement decreased the average crack spacing by $11 \%$, as shown in Table 4 . Also, the value of the average crack width for panels HS-U-20-2.5-4, and HS-U-20-2.5-4* reaches approximately $0.165 \mathrm{~mm}$ and $0.186 \mathrm{~mm}$, respectively, at the service stress level in reinforcement $\left(2 / 3 f_{y}\right)$ (ACI 318R-05). Therefore, the presence of the transverse reinforcement decreased the average crack width at the serviceability limit by $13 \%$.

\section{Steel stress after cracking}

Yielding of a reinforced concrete panel occurs when the steel stress at the cracked section reaches the yield strength of the reinforcement $\left(\sigma_{\mathrm{s} 0}=f_{y}\right)$. The value of the steel stress at the cracking section $\sigma_{\mathrm{s} 0}$ can be related to the average value of the steel stress embedded in the concrete section, Eq. (24) can be written as follows:

$$
\sigma_{s 0}=\frac{1}{\rho} \sigma_{x}+\alpha \sigma_{s}
$$

$\sigma_{x}$ in Eq. (26) represents the average value of concrete stress after cracking which is presented in Eq.(25) based on the experimental results as:

$$
\sigma_{x}=\sigma_{t}=f_{t}^{\prime} e^{\frac{-0.0008}{\alpha}\left(\varepsilon_{t}-\varepsilon_{t}^{\prime}\right)}
$$

Substituting with the value of $\sigma_{x}$ in Eq. (27) into Eq. (26), leads to:

$$
\sigma_{s 0}=\alpha \sigma_{s}+\frac{f_{t}^{\prime}}{\rho}\left[e^{\frac{-0.0008}{\alpha}\left(\varepsilon_{t}-\varepsilon_{t}^{\prime}\right)}\right]
$$

Since $f_{t}^{\prime}, \varepsilon_{t}^{\prime}$, and $\mathrm{E}_{\mathrm{s}}$ are determined material properties, $\varepsilon_{t}$ is the measured member strain $(\Delta / \mathrm{L})$, and $\rho$ is known, thus, Eq. (28) relates the steel stress at crack $\sigma_{\mathrm{s} 0}$ to the average steel stress embedded in the concrete $\sigma_{\mathrm{s}}$. In the above approach, the average steel stress embedded in the concrete section $\sigma_{\mathrm{s}}$ can be evaluated in terms of the steel stress at the crack location, tensile strength of concrete, and reinforcement ratio. In the mean time, the average steel strain $\varepsilon_{s m}=\sigma_{\mathrm{s}} / \mathrm{E}_{\mathrm{s}}$ can be calculated.

Figure 11 (a, b, c, d, e, and d) shows the comparison between the experimental and theoretical values for the average steel stress at different loading stages for panels NS-U-15-2.5-6, NS-B-15-2.5-6, HS-U-15-2.5-6, HS-B-15-2.5-6, HS-U-20-2.5-6, and HS-B-20-2.5-6, respectively. Also, the experimental results conducted by Belarbi and Hsu (1994) are used as a further verification for the model developed in Eq.28, as shown in Fig. 12. A good agreement between the experimental and theoretical model are obtained, as illustrated in Figs. 11 and 12.

\section{Crack spacing and crack width for a concrete plate}

Consider a reinforced concrete member subjected to axial force as shown in Fig 13. When the stress in the concrete has never exceeded its tensile strength, the member is free from cracks, and the reinforcement and concrete undergo compatible strains. When the tensile strength in concrete is exceeded, primary cracks form in the region of maximum tensile stresses when the external loads reaches the cracking load. At the location of a crack, the tensile stress is assumed to be resisted completely by the reinforcement.

Consider a segment of reinforced concrete panel subjected to axial loading, which is greater than the cracking load $P_{c r}$, as illustrated in Fig. 13(a). The idealized cracked panel is assumed to consist of the effective tensile area of concrete $A_{c t}$, and the reinforcing steel area $A_{s t}$. In a section situated between two cracks, the bond between the concrete and reinforcing bars restrains the elongation of the steel. Thus, a part of the tensile force in the reinforcement at the crack is transmitted to the concrete situated between the cracks. 


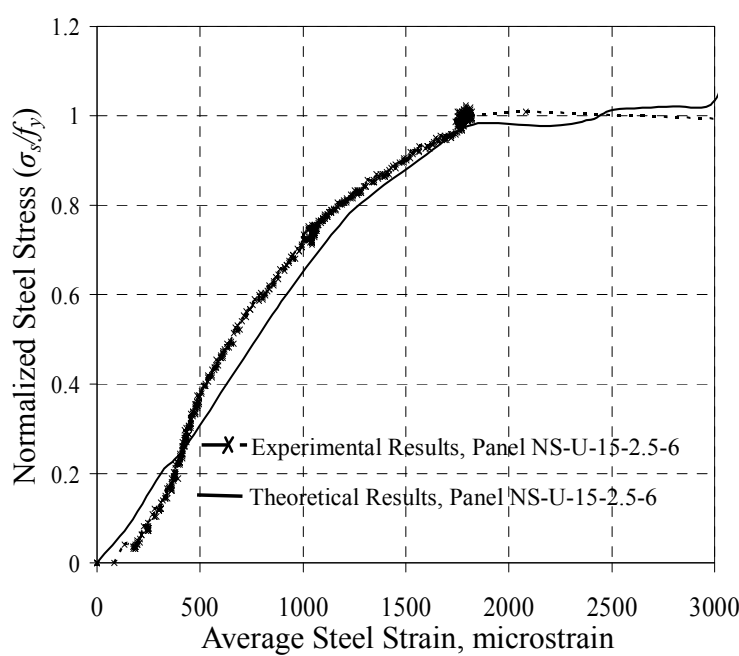

(a) Panel NS-U-15-2.5-6

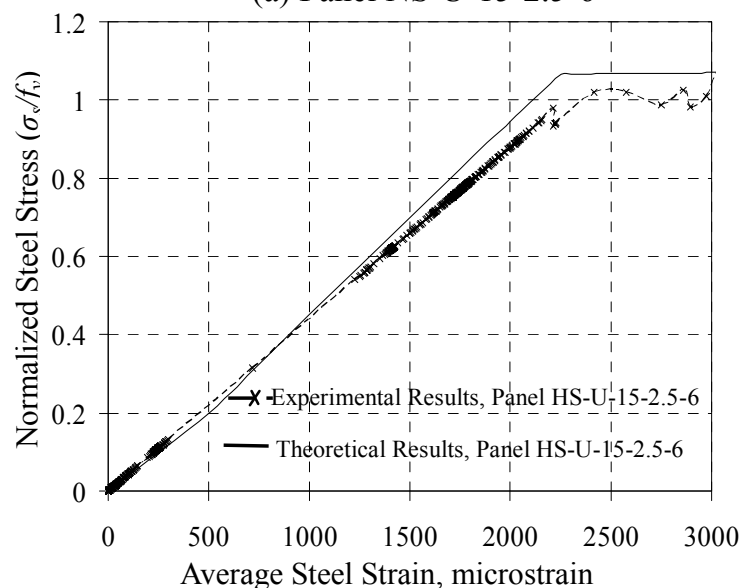

(c) Panel HS-U-15-2.5-6

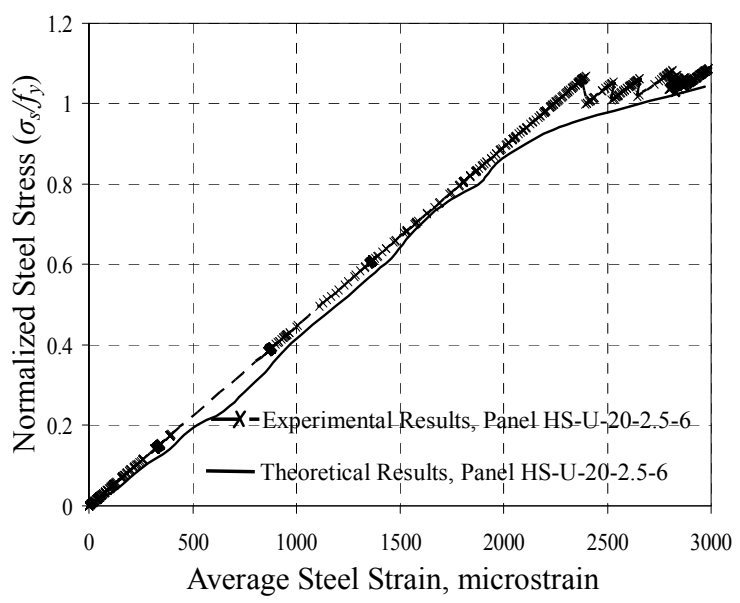

(e) Panel HS-U-20-2.5-6

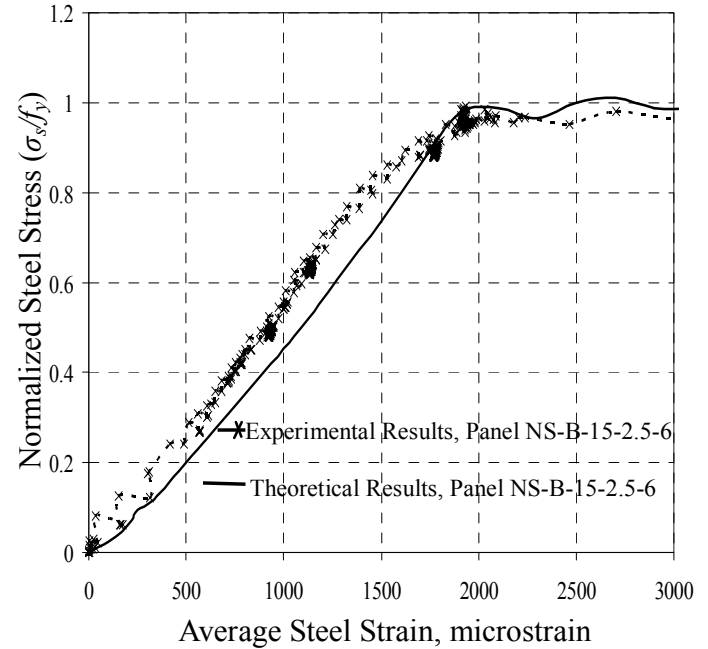

(b) Panel NS-B-15-2.5-6

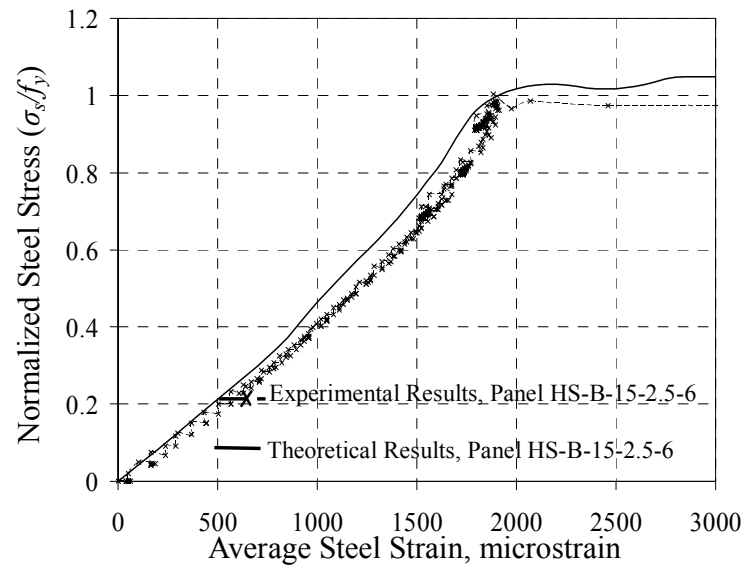

(d) Panel HS-B-15-2.5-6

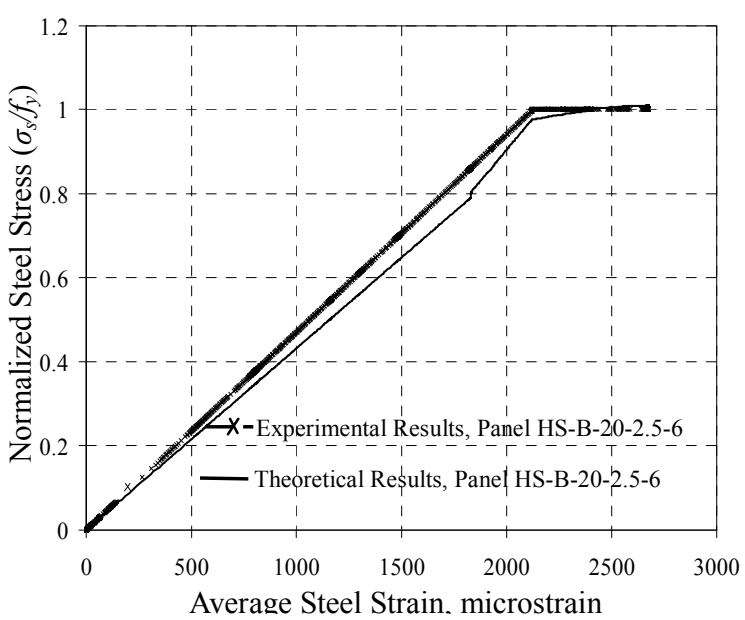

(f) Panel HS-B-20-2.5-6

Fig. 11 Comparison of theoretical and experimental values for the steel stress of reinforcing bars.

The equilibrium of a segment of the longitudinal chord representing the tensile zone between two consecutive cracks that is subjected to an axial tensile force $P$ is studied. The length of this segment $S$ represents the crack spacing.

Figure 13(a) shows a cross-section of a panel and the 


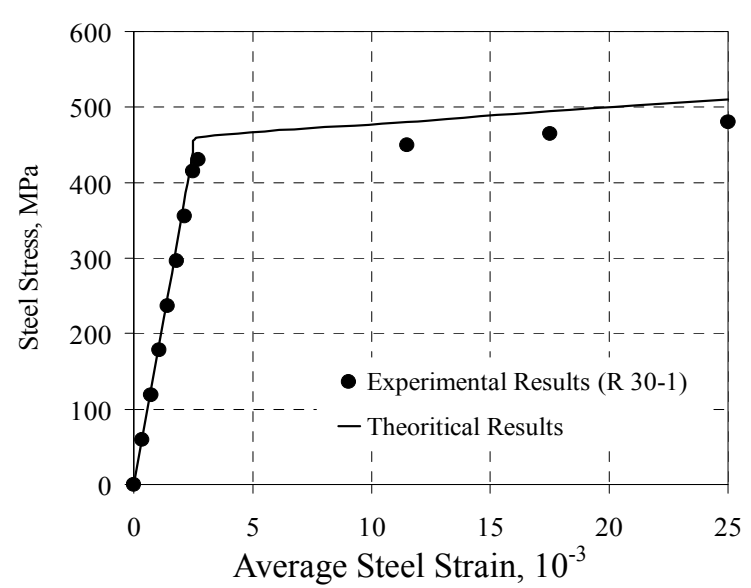

Fig. 12 Average stress-strain curve of reinforcing bars in panel R30-1.

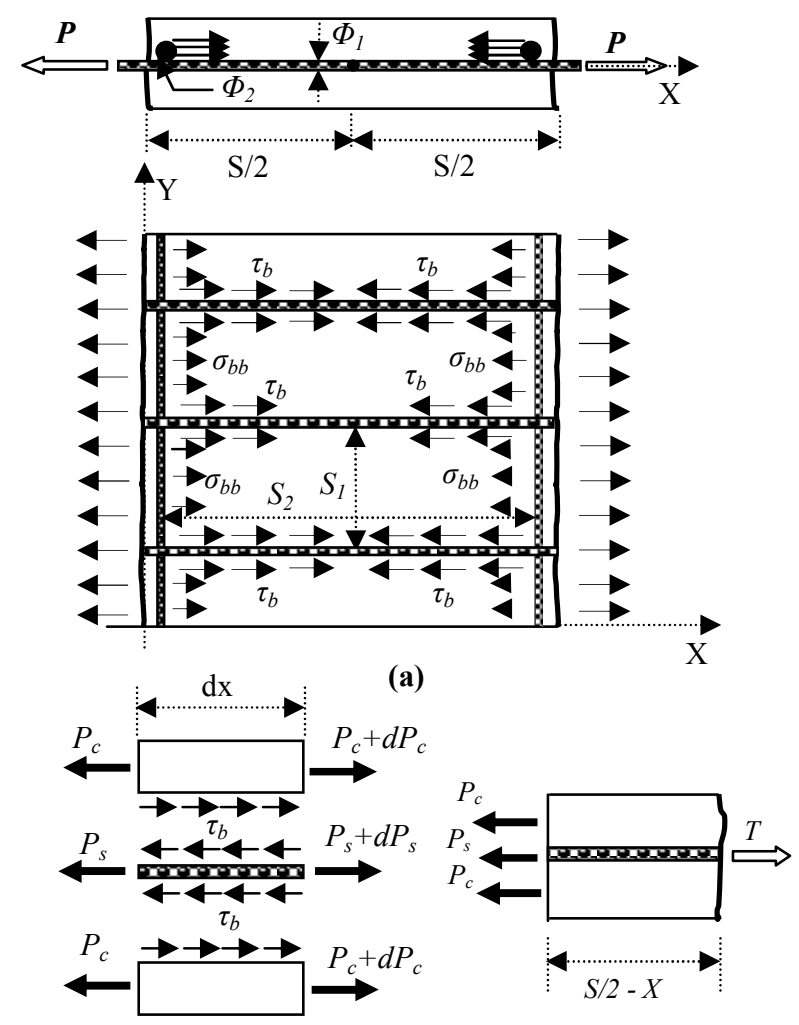

(b)

Fig. 13 Distribution of bond and bearing stresses over a concrete section.

layout of the reinforcement in $X$ and $Y$ directions. As a result of presence of the reinforcement in two-way perpendicular directions and considering a firm connection between the longitudinal and transverse reinforcements, when the load is applied in the $X$-direction and the bars are stretched, the surrounding concrete matrix resists the transverse bars, and the bars in the perpendicular direction can be assumed to bear against the surrounding concrete. The transverse bars in the perpendicular direction develop additional force component $\left[\sigma_{b b}(x) \Phi_{2} S_{I}\right]$ at the intersection between the longitudinal bars and the transverse bars. Considering the equilibrium of forces in $\mathrm{X}$-direction:

$$
P_{c}=P_{c}+d P_{c}-\left(\pi \phi_{1} d x\right) \tau_{b}-\sigma_{b b} \phi_{2} \frac{S_{1}}{S_{2}} d x
$$

The third term in Eq. (29) reflects the influence of the presence of the transverse bars, as it is assumed that the bearing force due to the existence of the transverse reinforcement is uniformly distributed along the longitudinal bar locations.

$$
\begin{aligned}
& \frac{d P_{c}}{d x}=\left(\pi \phi_{1} d x\right) \tau_{b}+\phi_{2} \frac{S_{1}}{S_{2}} \sigma_{b b} \\
& \frac{d \sigma_{c}}{d x}=\frac{\left(\pi \phi_{1}\right)}{A_{c t}} \tau_{b}+\frac{S_{1} \phi_{2}}{S_{2} A_{c t}} \sigma_{b b} \\
& \frac{d \sigma_{c}}{d x}=\frac{4 \rho}{\phi_{1}} \tau_{b}+\frac{S_{1} \phi_{2}}{S_{2} A_{c t}} \sigma_{b b} \\
& d \sigma_{c}=\frac{4 \rho}{\phi_{1}} \tau_{b} \cdot d x+\frac{S_{1} \phi_{2}}{S_{2} A_{c t}} \sigma_{b b} d x
\end{aligned}
$$

where $\sigma_{c}$ is the average value of the concrete stress, $\tau_{b}$ is the bond stress at the steel-concrete interface, $\rho$ is the effective reinforcement ratio (ratio of the tensile reinforcement area to the area of the effective concrete in tension), $\varnothing_{1}$ is the longitudinal bar diameter, $\varnothing_{2}$ is the transverse bar diameter, $S_{l}$ is the longitudinal bar spacing, and $S_{2}$ is the transverse bar spacing. Gilbert (2005), proposed that $\tau_{b}=\alpha_{1} \alpha_{2} f_{t}^{\prime}$, where $\alpha_{1}$ depends on the steel stress at the crack (and varies from 3.0 at low stress levels to 1.0 at high stress levels); and where $\alpha_{2}=1.0$ for short-term calculations and $\alpha_{2}=0.5$ for long-term calculations.

Concrete tensile stresses can not be greater than tensile strength $f_{t}^{\prime}$, so the requirement should be satisfied for the maximum crack spacing $S_{\max }$ in a fully developed crack pattern.

$$
\begin{aligned}
\sigma_{c} & =\int_{x=0}^{S / 2} \frac{4 \tau_{b} \rho_{\text {eff }}}{\phi_{1}} d x+\int_{x=0}^{S / 2} \frac{\sigma_{b b} \phi_{2} S_{1}}{A_{c t} S_{2}} d x \leq f_{t}^{\prime} \\
& =\left[\frac{4 \tau_{b} \rho_{e f f}}{\phi_{1}}\left(\frac{S}{2}\right)+\frac{\sigma_{b b} \phi_{2} S_{1}}{A_{c t} S_{2}}\left(\frac{S}{2}\right)\right] \leq f_{t}^{\prime}
\end{aligned}
$$

Therefore, the maximum crack spacing in a fully developed pattern may be expressed as:

$$
S_{\max }=f_{t}^{\prime} /\left[\frac{2 \tau_{b} \rho_{e f f}}{\phi_{1}}+\frac{\sigma_{b b} \phi_{2} S_{1}}{2 A_{c t} S_{2}}\right]
$$

The second term in the parentheses represents the effect of the transverse reinforcement on the cracking behavior, and it is found that the influence of the transverse bar represents approximately $10 \%$ of the first term of the 
denominator between the parentheses.

As loading is increased, additional cracks will form. The number of cracks will be stabilized when the stress in the concrete no longer exceeds its tensile strength at further locations, regardless of load increase. This condition basically produces the absolute minimum crack spacing that can occur at high steel stresses; termed here as stabilized crack spacing (Gilbert, 2006). In this research, the stabilized crack spacing is assumed to be expressed as:

$$
S_{m}=\lambda S_{\max }
$$

where $\lambda$ is a factor which represents the ratio between the stabilized crack spacing at high steel stress value and the maximum crack spacing at the primary crack stage, and it is assumed to be equal to 0.67 (Gilbert 2004). In the proposed model for calculating the crack spacing, the tensile stress on the concrete is assumed to be uniformly distributed and calculated by dividing the load transferred to the concrete section by the effective area of concrete matrix around the steel reinforcement. In the mean time, the proposed model takes the effect of the transverse steel reinforcement bar diameter and the bar spacing in both perpendicular directions into account.

Once the average crack spacing is calculated, the corresponding average crack width can be obtained by the following expression for crack runs in a direction perpendicular to the main reinforcement in members subjected to an axial force:

$$
w_{m}=S_{m} \varepsilon_{s m}
$$

where $S_{m}$ is the average crack spacing; and $\varepsilon_{s m}$ is the average steel strain.

The final crack patterns for typical panels subjected to uniaxial and biaxial loading at the stabilized crack stage. The cracks are marked manually at each stage of loading throughout the experiment, as shown in Fig. 14.

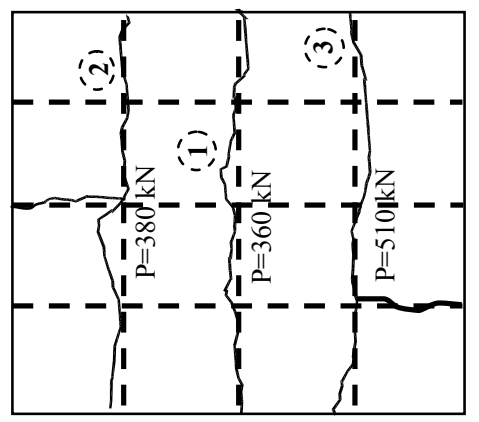

(a) Specimen HS-U-20-2.5-6

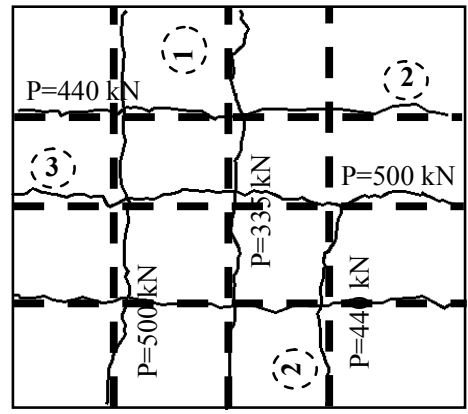

(b) Specimen HS-B-20-2.5-6

Fig. 14 Final crack patterns for the tested panels under uniaxial and biaxial loading.

\section{Experimental validation of the model}

To check the validity and accuracy of the proposed model for predicting the value of the crack spacing, a series of verification tests that involve various types of structural elements and loading conditions were performed to measure the reliability of the model in comparison with the experimental results. Table 4 represents a comparison of the average crack spacing of thick plates, between

\begin{tabular}{|c|c|c|c|c|c|c|}
\hline $\begin{array}{c}\text { Specimen } \\
\text { Serial }\end{array}$ & $\begin{array}{l}\text { Specimen } \\
\text { Number }\end{array}$ & $\begin{array}{c}\text { Measured Average } \\
\text { Crack spacing } \\
(\mathrm{mm})\end{array}$ & $\begin{array}{l}\text { Beeby } \mathrm{S}_{\mathrm{b}} \\
\text { Equation } \\
(\mathrm{mm})\end{array}$ & $\begin{array}{l}\text { Leonhard } \mathrm{S}_{\mathrm{L}} \\
\text { Equation } \\
(\mathrm{mm})\end{array}$ & $\begin{array}{l}\text { Rizkalla } \\
\text { Equation } \\
(\mathrm{mm})\end{array}$ & $\begin{array}{c}\text { Proposed } \\
\text { Model S } \\
(\mathrm{mm})\end{array}$ \\
\hline $1^{*}$ & Slab \#1 & 96.01 & 86.87 & 142.75 & 102.36 & 96.91 \\
\hline $2^{*}$ & Slab \#2 & 103.89 & 86.87 & 139.19 & 99.31 & 123.33 \\
\hline $3^{*}$ & Slab \#3 & 137.16 & 112.27 & 163.58 & 131.32 & 121.16 \\
\hline $4^{*}$ & Slab \#4 & 101.85 & 112.27 & 162.05 & 129.54 & 111 \\
\hline $5^{*}$ & Slab \#5 & 155.7 & 112.27 & 162.56 & 126.24 & 112.5 \\
\hline $6^{*}$ & Slab \#6 & 129.79 & 112.27 & 162.05 & 126.49 & 116.83 \\
\hline $7^{*}$ & Slab \#7 & 123.7 & 112.27 & 162.05 & 123.19 & 133.33 \\
\hline \multicolumn{3}{|c|}{ Mean $(\mu)$ for $S_{m(e x)} / S_{m(t h o .)}$} & 1.28 & 0.86 & 0.85 & 1.02 \\
\hline \multicolumn{3}{|c|}{ Standard Deviation $(\sigma)$ for $\mathrm{S}_{\mathrm{m}(\mathrm{ex})} / \mathrm{S}_{\mathrm{m}(\text { tho })}$} & 0.094 & 0.149 & 0.123 & 0.05 \\
\hline \multicolumn{3}{|c|}{ Coefficient of Variance $(\sigma / \mu)$ for $S_{\mathrm{m}(\mathrm{ex})} / \mathrm{S}_{\mathrm{m}(\text { tho })}$} & $7.4 \%$ & $17.2 \%$ & $14.4 \%$ & $4.9 \%$ \\
\hline
\end{tabular}

Table 5 Measured and calculated average crack spacing for experimental program conducted by Rizkalla at al. (1983).

\footnotetext{
"Experimental Program Conducted by Rizkalla et al. (1983, 1984).
} 
Table 6 Measured and calculated average crack spacing of reinforced concrete members loaded laterally.

\begin{tabular}{|c|c|c|c|c|c|c|}
\hline $\begin{array}{c}\text { Specimen } \\
\text { Serial }\end{array}$ & $\begin{array}{c}\text { Specimen } \\
\text { Number }\end{array}$ & $\begin{array}{c}\text { Measured Average } \\
\text { Crack spacing }(\mathrm{mm})\end{array}$ & $\begin{array}{c}\text { Beeby } \mathrm{S}_{\mathrm{m}} \\
\text { Equation } \\
(\mathrm{mm})\end{array}$ & $\begin{array}{c}\text { Leonhard } \mathrm{S}_{\mathrm{m}} \\
\text { Equation } \\
(\mathrm{mm})\end{array}$ & $\begin{array}{c}\text { Rizkalla } \\
\text { Equation } \\
(\mathrm{mm})\end{array}$ & $\begin{array}{c}\text { Proposed } \\
\text { Model S } \\
(\mathrm{mm})\end{array}$ \\
\hline $1^{*}$ & Slab NSC1 & 134 & 99.52 & 161.56 & 188.52 & 121 \\
\hline $2^{*}$ & Slab NSC2 & 223 & 173.82 & 218.42 & 212.82 & 235.3 \\
\hline $3^{*}$ & Slab NSC3 & 239 & 221.2 & 275.48 & 235.2 & 252.2 \\
\hline $4^{*}$ & Slab HSC1 & 171 & 126.12 & 172.7 & 215.12 & 142.1 \\
\hline $5^{*}$ & Slab HSC2 & 185 & 139.42 & 174.19 & 228.42 & 154.2 \\
\hline $6^{*}$ & Slab HSC3 & 163 & 119.47 & 204.71 & 208.47 & 161.4 \\
\hline $7^{*}$ & Slab HSC4 & 172 & 139.26 & 243.18 & 228.26 & 165.5 \\
\hline $8^{*}$ & Slab HSC5 & 120 & 96.15 & 184.12 & 135.15 & 112.3 \\
\hline \multicolumn{2}{|c|}{ Mean $(\mu)$ for $\mathrm{S}_{\mathrm{m}(\mathrm{ex})} / \mathrm{S}_{\mathrm{m}(\mathrm{tho})}$} & 1.28 & 0.86 & 0.85 & 1.02 \\
\hline \multicolumn{2}{|c|}{ Standard Deviation $(\sigma)$ for $\mathrm{S}_{\mathrm{m}(\mathrm{ex})} / \mathrm{S}_{\mathrm{m}(\mathrm{tho})}$} & 0.094 & 0.149 & 0.123 & 0.06 \\
\hline
\end{tabular}

* Experimental Program Conducted by Hossin and Marzouk (2008).

the results of the experimental works conducted in the present study and the analytical model proposed in Eq. (35), as well as the previously proposed model equations derived by (Leonhardt 1977; Beeby 1972; and Rizkalla et al. 1983). To enable an accurate crack spacing measurements to be obtained, the tested panels were carefully inspected at each load step. The cracks were marked manually on all specimens at each load increment. Crack mapping of the specimen was depicted by means of photographs at each stage of loading throughout the experiment. These photographs were imported into a computer-aided AutoCAD tools, and the spacing was measured at different locations of the cracked panels to increase the accuracy of the measured average crack spacing.

Furthermore, the proposed Eq. (35) is used to predict the value of the crack spacing for previous experimental works. This is to ensure the suitability of the proposed model for evaluating the value of the average crack spacing for various reinforced concrete members under different types of loading conditions. The previous experimental works involved direct tension tests carried out by (Rizkalla et al. 1983) which are represented in Table $\mathbf{5}$, and laterally loaded slabs tested by (Hossin and Marzouk 2006) which are presented in Table 6.

The proposed model in Eq. (35) for the crack spacing takes into account the effect of the concrete tensile strength, bar spacing, bar diameter, transverse reinforcement and bond stress, which represent most of the factors that affect the cracking behavior of the reinforced concrete specimens.

It is noted that the model proposed by Leonhardt overestimates the value of the crack spacing. However, the approach suggested by Beeby underestimates the value of the crack spacing as compared with the experimental results. Thus, it might be concluded that neither of these two expressions is accurate for predicting

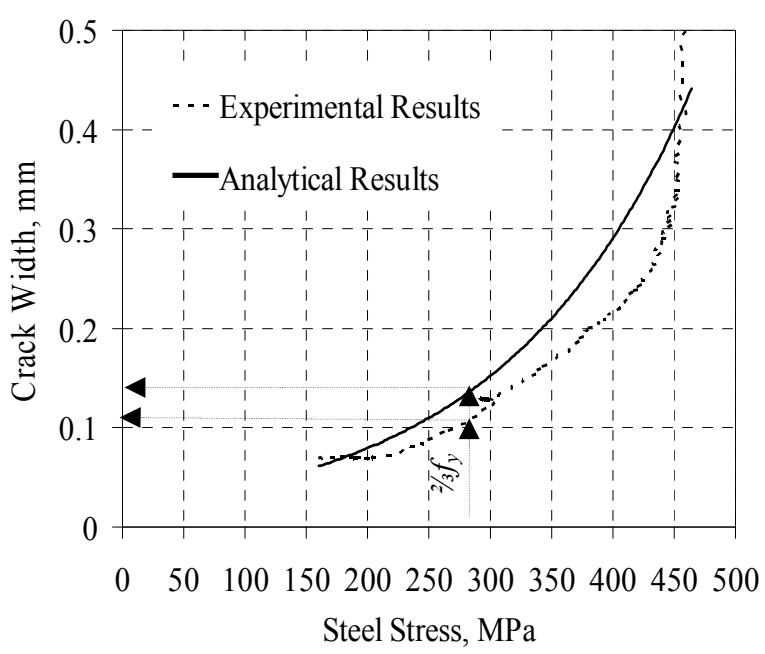

Fig. 15 Average crack widths versus steel stress for panel HS-U-20-2.5-6.

the value of the crack spacing for offshore structures which include the presence of a transverse reinforcement and thick concrete cover. In the mean time, the model recommended by Rizkalla offers reasonable results, as the reinforced structures have a small bar diameter, such as $10 \mathrm{M}$, and $15 \mathrm{M}$. However, when a higher bar diameter, such as $20 \mathrm{M}$ and $25 \mathrm{M}$ is used, as it is common in offshore structures, the model starts to overestimate the value of the crack spacing. This model magnifies the influence of the bar diameter, so when a higher bar diameter is used, the final value of the crack spacing becomes higher in comparison to the experimental values.

Statistical comparisons are presented in Tables 4 through 6 between the proposed model in Eq. (35) and the previously developed models by Beeby, Leonhard, and Rizkalla, at the stabilized crack pattern. These tables show that the proposed model in Eq.35 gives the lowest 
Table 7 Measured and calculated average crack width at service load $(2 / 3 f y)$.

\begin{tabular}{|c|c|c|c|c|c|}
\hline Segment & $f_{c}^{\prime}, \quad \mathrm{MPa}$ & $\begin{array}{c}f_{t}^{\prime}, \\
\mathrm{MPa}\end{array}$ & $\begin{array}{c}\text { Measured Average } \\
\text { Crack Width } w_{m(e x)}, \\
\mathrm{mm}\end{array}$ & $\begin{array}{c}\text { Calculated Aver- } \\
\text { age Crack Width } \\
w_{m(c a l .)}, \\
\mathrm{mm}\end{array}$ & $\begin{array}{c}{\left[w_{m(e x)-}\right.} \\
w_{m(c a l .)] /} \\
w_{m(c a l .} \%\end{array}$ \\
\hline$\# 1^{*}$ & 35.1 & 2.12 & 0.084 & 0.094 & 12 \\
\hline$\# 2^{*}$ & 30.7 & 1.2 & 0.068 & 0.073 & 7 \\
\hline$\# 3^{*}$ & 39.2 & 1.6 & 0.094 & 0.108 & 14 \\
\hline$\# 4^{*}$ & 39.2 & 1.79 & 0.098 & 0.114 & 16 \\
\hline$\# 5^{*}$ & 38.5 & 2.68 & 0.133 & 0.148 & 11 \\
\hline$\# 6^{*}$ & 39.2 & 1.54 & 0.099 & 0.114 & 12 \\
\hline$\# 7^{*}$ & 31.3 & 1.16 & 0.14 & 0.152 & 8 \\
\hline$\# 8^{*}$ & 16.5 & 2.21 & 0.16 & 0.144 & 13 \\
\hline$\# 9^{*}$ & 25.6 & 1.52 & 0.076 & 0.087 & 14 \\
\hline$\# 11^{*}$ & 33.9 & 1.17 & 0.081 & 0.092 & 13 \\
\hline$\# 12^{*}$ & 40.9 & 2.01 & 0.087 & 0.095 & 9 \\
\hline$\# 13^{*}$ & 42.3 & 2.07 & 0.12 & 0.119 & 8 \\
\hline
\end{tabular}

*Experimental Program Conducted by MacGroger et al. (1980).

value for the standard deviation $\sigma$.

Figures 15 and $\mathbf{1 6}$ present a comparison of the average value for the crack width for different steel stress levels, between the experimentally obtained results and the predicted values of the crack width based on Eq. (36) for panels HS-U-20-2.5-6 and NS-U-15-2.5-6, respectively.

For panel HS-U-20-2.5-6 at a steel stress of $270 \mathrm{MPa}$ $\left(2 / 3 f_{y}\right)$, corresponding to steel stress at the service load (ACI 318R-05), the measured crack width is found 0.089 $\mathrm{mm}$, and the calculated value for the crack width based on Eq.(36) is found equal to $0.121 \mathrm{~mm}$, as shown in Fig. 15. For panel NS-U-15-2.5-6, at service load level the measured crack width is found to be $0.19 \mathrm{~mm}$, and the calculated value is $0.211 \mathrm{~mm}$, as shown in Fig. 16. A satisfactory agreement between the experimental results and calculated values of the average crack width using the proposed Eq. (36), as shown in Figs. 15 and 16.

Furthermore, the available test data conducted at University of Alberta, Canada, by James McGregor (1980) are used as a further verification for the proposed equation for calculating the average crack width in Eq. (36), as presented in Table 7.

\section{Conclusions}

In this paper, a rational tension stiffening model which expresses the pre- and post-cracking stress-strain relationship for reinforced concrete members under tension, is developed. The tension stiffening characterization is incorporated in an equilibrium equation to model the stress response of the reinforcement embedded in the concrete section. Tension stiffening effect in reinforced concrete is an important characteristic for consideration if an accurate cracking behavior of reinforced concrete is desired. This is achieved through incorporating the average tensile stress strain relationship of concrete in the

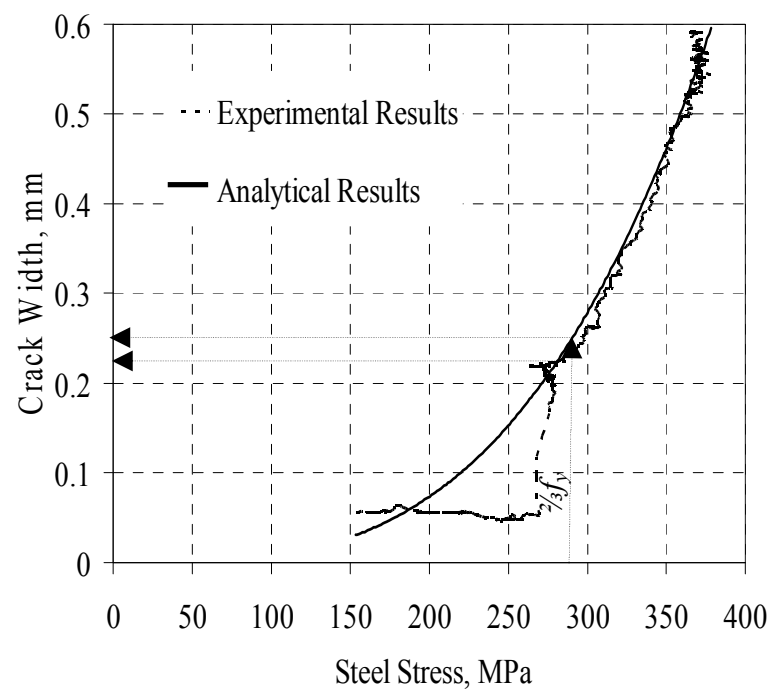

Fig. 16 Average crack widths versus steel stress for panel NS-U-15-2.5-6.

analysis. Moreover, the cracking behavior of concrete in axially loaded reinforced concrete panels, which includes the crack spacing and width, is modeled. An experimental investigation is carried out to examine the tensile stress-strain relationship for concrete in tension, also, to verify the accuracy of the proposed model for the crack spacing and width. Based on this study, the following conclusions can be drawn:

1- The ascending portion of the tensile stress-strain curve, which is the region before cracking, can be approximated as a straight line. This pre-cracking relation can be normalized by dividing $f t$ and $\varepsilon t$ by $f t^{\prime}$ and the average observed value of cracking strain, respectively,

$$
\frac{\sigma_{t}}{f_{t}^{\prime}}=\frac{\varepsilon_{t}}{102 \times 10^{-6}}
$$


2- The tension stiffening of concrete plates under tension can be represented by the descending portion of the tensile stress-strain curve and can also be modeled as an exponential function as follows:

$$
\frac{\sigma_{t}}{f_{t}^{\prime}}=e^{\frac{-0.0008}{\alpha}\left(\varepsilon_{t}-\varepsilon_{t}^{\prime}\right)}
$$

3- The average stresses for the steel bars embedded in the concrete matrix can be determined by using the following equation:

$$
\sigma_{s 0}=\alpha \sigma_{s}+\frac{f_{t}^{\prime}}{\rho}\left[e^{\frac{-0.0008}{\alpha}\left(\varepsilon_{t}-\varepsilon_{t}^{\prime}\right)}\right]
$$

where this equation relates the $\sigma_{\mathrm{s} 0}$ steel stress at crack location to the average steel stress $\sigma_{\mathrm{s}}$ embedded in the concrete. A factor $\alpha$ reflects the influence of the transverse bar on the steel stress distribution, is considered, where the value of $\alpha$ is found to be equal to approximately between $0.92-0.95$.

4- In this paper, a rational crack spacing model is developed by considering the equilibrium of reinforced concrete elements. The proposed analytical model for maximum crack spacing can be expressed as follows:

$$
S_{\max }=f_{t}^{\prime} /\left[\frac{2 \tau_{b} \rho_{e f f}}{\phi_{1}}+\frac{\sigma_{b b} \phi_{2} S_{1}}{2 A_{c t} S_{2}}\right]
$$

5- The proposed model for the cracking width is:

$$
w_{m}=S_{m} \varepsilon_{s m}
$$

where $S_{r m}$ is the average crack spacing; and $\varepsilon_{s m}$ is the average steel strain

\section{Acknowledgements}

This research is granted by the Natural Science and Engineering Council of Canada (NSERC) and received with appreciation. Sincere thanks are due to the members of the Technical Services at the Memorial University for their assistance during conduction of the experimental program. The authors express their gratitude and appreciation to the technical staff of the Structural Engineering Laboratory at the Memorial University for their assistance during testing, especially M. Curtis and S. Organ. Sincere thanks are extended to Capital Ready Mix Ltd., Newfoundland, for providing the concrete for this project.

\section{Notations:}

$A_{c t}: \quad$ Effective tensile area of concrete

$\mathrm{A}_{\mathrm{st}}$ : Reinforcing steel area

$\alpha$ : $\quad$ Factor reflects the effect of the transverse reinforcement on the steel stress $(0.92-0.95)$

$\mathrm{E}_{\mathrm{c}}$ : Young's modulus for concrete

$\varepsilon_{t}^{\prime}$ : Cracking strain of concrete $\varepsilon_{t}: \quad$ Measured member strain $(\Delta / \mathrm{L})$

$\varepsilon_{\mathrm{sx}}$ : Average tensile strain of reinforcement between two consecutive cracks

$f_{t}^{\prime}$ : $\quad$ Tensile strength of concrete

$\emptyset_{1}$ : $\quad$ Longitudinal bar diameter

$\varnothing_{2}$ : Transverse bar diameter

$\lambda$ : $\quad$ Factor represents the ratio between the stabilized crack spacing at high steel stress and the maximum crack spacing at the primary cracks stage

$\mathrm{P}_{\mathrm{c}}$ : Load carried by the concrete section

$\mathrm{P}_{c r}$ : Cracking load

$\mathrm{P}_{\mathrm{s}}$ : $\quad$ load carried by the reinforcement

$\rho: \quad$ Effective reinforcement ratio

$S_{I}: \quad$ Longitudinal bar spacing

$S_{2}: \quad$ Transverse bar spacing

$\mathrm{S}_{\max }: \quad$ Maximum crack spacing

$\mathrm{S}_{\mathrm{m}}: \quad$ Average crack spacing

$\sigma_{b b}: \quad$ Bearing stress

$\sigma_{c}(x)$ : Local stress of concrete at distance $\mathrm{x}$ from given crack

$\sigma_{\mathrm{s}}$ : Average tensile stress of reinforcement between two consecutive cracks

$\sigma_{\mathrm{s} 0}$ : Tensile stress of reinforcing bar at cracked sections

$\sigma_{\mathrm{s}}(\mathrm{x})$ : Local stress of reinforcing bar at distance $\mathrm{x}$ from given crack

$\sigma_{s c r}: \quad$ Steel stress at cracking Stage

$\sigma_{\mathrm{x}}=\sigma_{t}:$ Average concrete stress after cracking

$\tau_{\mathrm{b}}$ : $\quad$ Bond stress at steel-concrete interface

$w_{\mathrm{m}}$ : Average crack width

\section{References}

ACI Committee 318 (2005). "Building code requirements for structural concrete (ACI 318-05) and commentary (ACI 318R-05)." American Concrete Institute, Farmington Hills, Mich., 126.

ACI Committee 363 (1984). "State of the-art report on high-strength concrete.” ACI Structural Journal, 81(4), 364-411.

Architectural Institute of Japan, (1985). "Standard for structural calculation of reinforced concrete structures." Chapter 2, AIJ, 8-11.

Alavi-Fard, M. and Marzouk, H. (2002). "Bond behavior of high strength concrete under reversed pull-out cyclic loading." Canadian Journal of Civil Engineering, 29, 191-200.

Beeby, A. W. (1972). "A study of cracking in reinforced concrete members subjected to pure tension." Technical Report 42.468, Cement and Concrete Association, London.

Belarbi, A. and Hsu, T. T. (1994). "Constitutive laws of concrete in tension and reinforcing bars stiffened by concrete." ACI Structural Journal, 91(4), 465-474.

Cho, J.Y., Kim, N. S., Cho, N. S., and Choi, I. K., (2004a). "Cracking behavior of reinforced concrete panel subjected to biaxial tension.” ACI Structural Journal, 101(1), 76-84. 
Cho, J. Y., Kim, N. S., Cho, N. S. and Choun Y. S. (2004b). "Stress-strain relationship of reinforced concrete subjected to biaxial tension." ACI Structural Journal, 101(2), 202-208.

Comité Euro-International du Béton (1995). "High-performance concrete, recommended extensions to the model code 90-research needs." CEB Bulletin d'Information, No.228, 48.

Dawood, N. and Marzouk, H. (2008). "Cracking behavior of high strength concrete panels under uniaxial and biaxial loading." 1 st International Structural Specialty Conference, 37th Annual Conference for the Canadian Society for Civil Engineering, Quebec City, 1-10.

Desayi, P. and Kulkarni, A. B., (1976). "Determination of maximum crack width in two-way reinforced concrete slabs." Proceedings, Inst. of Civil Engineers (London), Part 2, Research and Theory, 61, 343-349.

EC2 (2004). "Eurocode 2-Design of concrete structuresPart I: General rules and rules for building." European Committee for Standardization, Paris, 225.

Fields, K. and Bischoff, P. H. (2004). "Tension stiffening and cracking of high-strength reinforced concrete tension members." ACI Structural Journal, 101(4), 447-456.

Ghali A., Favre R. and Elbadry, M. (2002). "Concrete structures: stresses and deformations." $3^{\text {rd }}$ edition, New York: Spon Press, 380-554.

Gilbert, R. I. (2005). "Time-dependent cracking and crack control in reinforced concrete structures." $A C I$ Structural Journal, Special Publication, 225(15), 223-244.

Gilbert, R. I. (2006). "Design for flexural crack control-recent amendments to the Australian standard AS3600." $1^{\text {st }}$ International Structural Specially Conference, Calgary, Alberta, Canada, 1-10.

Gilbert, R. I. (2008). "Control of flexural cracking in reinforced concrete." ACI Structural Journal, 105(3), 301-307.

Hossin, M. A. and Marzouk, H. (2008). "Crack spacing for offshore structures." Canadian Journal of Civil Engineering, 35(12), 1446-1454.

Hsu, T. T. and Zhang, L. X. (1996). "Tension stiffening in reinforced concrete membrane elements." $A C I$ Structural Journal, 93(1), 108-115.

Leonhardt, F. (1977). "Crack control in concrete structures." IABSE Surveys, No.S-4/77, IABE Periodical 3/1977, International Association for Bridge and structural Engineering Zurich, Switzerland, 26.

MacGregor, J. G., Rizkalla S. H. and Simmonds S. H. (1980). "Cracking of reinforced and prestressed concrete wall segments." Structural Engineering Report No. 82, Department of Civil Engineering, University of Alberta, Edmonton, Alberta.

Marzouk, H. and Chen, Z. W. (1993). "Nonlinear analysis of normal- and high-strength concrete slabs." Canadian Journal of Civil Engineering, 20(4), 696-707.

Marzouk, H. and Chen Z. W. (1995). "Fracture energy and tension properties of high-strength concrete." Journal of Material in Civil Engineering, 7(2), 108-116.

Maekawa, K., Pimanmas, A. and Okamura, H. (2003). "Nonlinear mechanics of reinforced concrete." Spon Press, London, New York, 27-30.

Rizkalla, S. H., Hwang L. S. and EL Shahwi, M. (1983). "Transverse reinforcement effect on cracking behavior of R.C. members." Canadian Journal of Civil Engineering, 10(4), 556-581.

Riakalla, S. H. and Hwang, L. S. (1984). "Crack perdition for members in uniaxial tension." $A C I$ Structural Journal, 81(4), 572-579.

Shima, H., Chou, L. and Okamura, H. (1987). "Micro and macro models for bond behavior in reinforced concrete." Journal of Faculty of Engineering, University of Tokyo (B), 39(2), 178-186.

Williams, A. (1986). "Tests on large reinforced concrete elements subjected to direct tension." Cement and Concrete Association, Technical Report 562:1-55. 